\title{
Association between the -112G/A polymorphism of uteroglobulin-related protein 1 gene and asthma risk: A meta-analysis
}

\author{
HAOJUN XIE ${ }^{1}$, MULI WU ${ }^{2}$, BIN SHEN $^{1}$, YI NIU ${ }^{1}$, YATING HUO ${ }^{1}$ and YUANXIONG CHENG ${ }^{1}$ \\ Departments of ${ }^{1}$ Respiratory and Critical Care Medicine and ${ }^{2}$ Cardiology, Nanfang Hospital, \\ Southern Medical University, Guangzhou, Guangdong 510515, P.R. China
}

Received July 28, 2013; Accepted December 6, 2013

DOI: $10.3892 /$ etm.2014.1471

\begin{abstract}
The aim of this study was to investigate the correlation between the $-112 \mathrm{G} / \mathrm{A}$ polymorphism of the uteroglobulin-related protein 1 (UGRP1) gene and asthma risk using meta-analysis. PubMed, BIOSIS Previews and EBSCOhost were searched, and data were extracted independently by two reviewers. Odds ratios (ORs) with corresponding 95\% confidence intervals (CIs) were used to assess the strength of the associations. Statistical analysis was performed using Review Manager 5.2 and STATA 11.0 software. Six studies, involving 816 cases and 1,165 controls, were included in the analysis. The meta-analysis showed a significant correlation between the UGRP1-112G/A polymorphism and asthma for AA versus GG $(\mathrm{P}=0.01)$ and AA versus $\mathrm{GA} / \mathrm{GG}(\mathrm{P}=0.02)$. Furthermore, stratification by ethnicity revealed a significant correlation between the $-112 \mathrm{G} / \mathrm{A}$ polymorphism and asthma for $\mathrm{A}$ versus $\mathrm{G}(\mathrm{P}=0.02)$, AA versus $\mathrm{GG}(\mathrm{P}=0.01)$ and $\mathrm{AA}$ versus $\mathrm{GA} / \mathrm{GG}$ $(\mathrm{P}=0.03)$ in Asians, but not in Caucasians. When stratified by atopy, a significant correlation was observed for A versus $G$ $(\mathrm{P}=0.02)$ and $\mathrm{AA} / \mathrm{GA}$ versus $\mathrm{GG}(\mathrm{P}=0.04)$ in the mixed group. No correlation was observed for age stratification. Results of the current meta-analysis indicate that the $-112 \mathrm{G} / \mathrm{A}$ polymorphism of the UGRP1 gene is likely to contribute to asthma risk, particularly in the Asian population.
\end{abstract}

\section{Introduction}

Asthma is a common global public health concern, affecting $\sim 300$ million people worldwide (1). It is a complex disease, which is the result of interactions between genetic and envi-

Correspondence to: Dr Yuanxiong Cheng, Department of Respiratory and Critical Care Medicine, Nanfang Hospital, Southern Medical University, 1838 North Guangzhou Avenue, Guangzhou, Guangdong 510515, P.R. China

E-mail: drchengyx@yahoo.com.cn

Key words: uteroglobulin-related protein 1 gene, asthma, polymorphism, meta-analysis ronmental factors (2). Investigation of the correlation between genetic variants and asthma risk has identified numerous genes conferring susceptibility to asthma (3); among these, the uteroglobulin-related protein 1 (UGRP1) gene has been extensively studied.

The gene encoding UGRP1, a secreted protein, was first identified by Niimi et al (4). The human UGRP1 gene is located on chromosome 5q31-32, a region containing a number of candidate genes that may play a role in asthma and other allergic diseases. These genes encode proinflammatory cytokines, such as interleukin-3, -4, -5, -9 and -13 (5). As a result of the similarity in the amino acid sequences of UGRP1 and Clara cell protein (CC16), which exhibits several immunomodulatory and anti-inflammatory effects, it is possible that UGRP1 may possess similar functions (6). Furthermore, UGRP1 mRNA is predominantly expressed in the lung, with a high level of expression in the epithelial cells of the lung airway (4). These observations suggest that the UGRP1 gene may be important in the pathogenesis of asthma.

Previous studies have investigated the association between the $-112 \mathrm{G} / \mathrm{A}$ polymorphisms of the UGRP1 gene and asthma risk. However, while certain studies have described a significant association (4,7), no such association was observed in other studies (8-12). Since a single study may lack the robust power to provide a reliable conclusion, in the present study, a comprehensive search of the literature and a meta-analysis was performed to examine whether UGRP1 gene polymorphisms contribute to asthma susceptibility.

\section{Materials and methods}

Publication search. Pubmed, BIOSIS Previews and EBSCOhost were comprehensively searched, with the last search updated on March 12, 2013. The Medical Subject Heading terms and/or text words utilized were 'asthma' or 'bronchial hyperreactivity' or 'respiratory hypersensitivity' or 'bronchial asthma', in combination with 'polymorphism*' or 'variant*' or 'genetic' or 'mutant*' and in combination with 'SCGB3A2' (secretoglobin, family 3A, member 2) or 'UGRP1' or 'Clara cell secretory protein-related protein'. No publication language restrictions were imposed. All the searched studies were retrieved, and their references were 
Table I. Search strategies.

\begin{tabular}{|c|c|c|}
\hline Database & Time span & Search strategies \\
\hline Pubmed & 1966-March 12, 2013 & 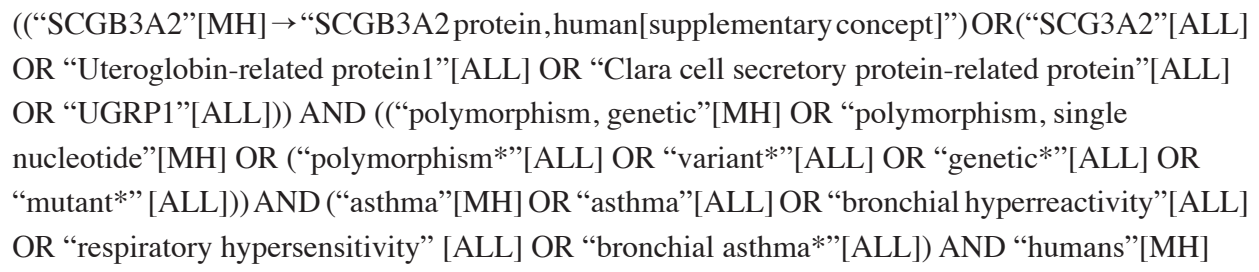 \\
\hline EBSCOhost & 1997-March 8, 2013 & $\begin{array}{l}\text { (asthma[subject terms] OR asthma[all text] OR "bronchial asthma"[all text] OR "bronchial } \\
\text { hyperreactivity"[all text] OR "respiratory hypersensitivity"[all text]) AND (polymorphism[subject } \\
\text { terms] OR polymorphism[all text] OR "genetic polymorphism"[all text] OR "single nucleotide } \\
\text { polymorphism"[all text] OR variant*[all text] OR mutant*[all text]) AND (SCG3A2[all text] OR } \\
\text { "Uteroglobin-related protein1"[all text] OR "Clara cell secretory protein-related protein" [all text]) }\end{array}$ \\
\hline BIOSIS Previews & 1950-March 12, 2013 & $\begin{array}{l}\text { \#1. Topic }=(\text { UGRP1 }) \text { OR Topic }=(\text { SCGB3A2 }) \text { OR Topic }=(\text { Uteroglobin-related protein1 }) \text { OR } \\
\text { Topic }=(\text { Clara cell secretory protein-related protein }) \\
\text { \#2. Topic }=(\text { polymorphism } *) \text { OR Topic }=(\text { variant } *) \text { OR Topic }=\left(\text { mutant*) OR Topic }=\left(\text { genetic }^{*}\right)\right. \\
\text { \#3. Topic }=(\text { asthma }) \text { OR Topic }=(\text { bronchial asthma }) \text { OR Topic }=(\text { bronchial hyperreactivity }) \text { OR } \\
\text { Topic }=(\text { respiratory hypersensitivity }) \\
\text { \#4. \#1 AND \#2 AND \#3 }\end{array}$ \\
\hline
\end{tabular}

SCGB3A2, secretoglobin, family 3A, member 2 .

checked for other relevant publications. The search strategy for the study is shown in Table I.

Inclusion and exclusion criteria. Human studies were included if they met the following criteria: i) Evaluation of the $-112 \mathrm{G} / \mathrm{A}$ polymorphism of the UGRP1 gene and asthma risk; ii) using a case-control design; and iii) genotype distributions in comparison groups were available for estimating an odds ratio (OR) with $95 \%$ confidence interval (CI). Studies were excluded if one of the following existed: i) Not relevant to UGRP1 gene polymorphisms or asthma risk; ii) design based on family or sibling pairs; and iii) reviews or abstracts. When the same patient population was included in several publications, only the most complete study was included in the meta-analysis. If the original data for the genotype frequencies were unavailable in the relevant studies, an email was sent to the corresponding author for additional data.

Data extraction. Two investigators (Xie and $\mathrm{Wu}$ ) independently reviewed the full manuscripts of the eligible studies, and data were extracted independently into a predesigned data collection form. The accuracy of the data was verified by comparing the collection forms from each investigator. Disagreements were resolved by discussion or by a third author (Cheng) assessing the articles. The following information was collected from each study: First author's name, year of publication, original country, ethnicity, sample size, asthma definition, genotyping method, atopic status and genotype numbers in the cases and controls.

Quality score evaluation. The quality score evaluation was performed in accordance with a previous study (13). Briefly, the following variables were assessed: Representativeness of cases and controls, ascertainment of asthma and controls, geno- typing examination, Hardy-Weinberg equilibrium (HWE), association assessment and response rate. The quality score had a maximum of 15 points. The higher the study scored, the better the quality was. Studies with quality scores $<4$ were excluded (14). All studies included in our meta-analysis were of a high quality (Table II).

Publication bias. The publication bias of the studies was assessed using Begg's funnel plots, and $\mathrm{P}<0.05$ was considered to indicate a statistically significant difference. Since this method required a range of studies with varying sizes and subjective judgments (14), publication bias was also evaluated using Egger's linear regression test.

Statistical analysis. Departures from the HWE in the control groups were assessed using the $\chi^{2}$ test. The meta-analyses were performed using the following models: i) Allelic (A versus $\mathrm{G}$ ); ii) additive (AA versus $\mathrm{GG}$ ); iii) recessive (AA/AG versus GG); and iv) dominant (AA versus AG/GG). Subgroup analyses were conducted according to ethnicity, age and atopic status. The heterogeneity between the studies was assessed using the $\chi^{2}$ test, based on the Cochrane Q-test. In addition, $\mathrm{I}^{2}$ was used to examine the heterogeneity among the included studies. $\mathrm{P}>0.10$ for the Q-test indicated a lack of heterogeneity among the studies. The pooled OR estimate of each study was then calculated using the fixed effects model. Otherwise, the random effects model was used.

All statistical tests were performed using Review Manager software (version 5.2; The Nordic Cochrane Center, Copenhagen, Denmark) and STATA 11.0 software (Stata Corp., College Station, TX, USA). $\mathrm{P}<0.05$ was considered to indicate a statistically significant difference, with the exception of heterogeneity tests where a level of 0.10 was used. 


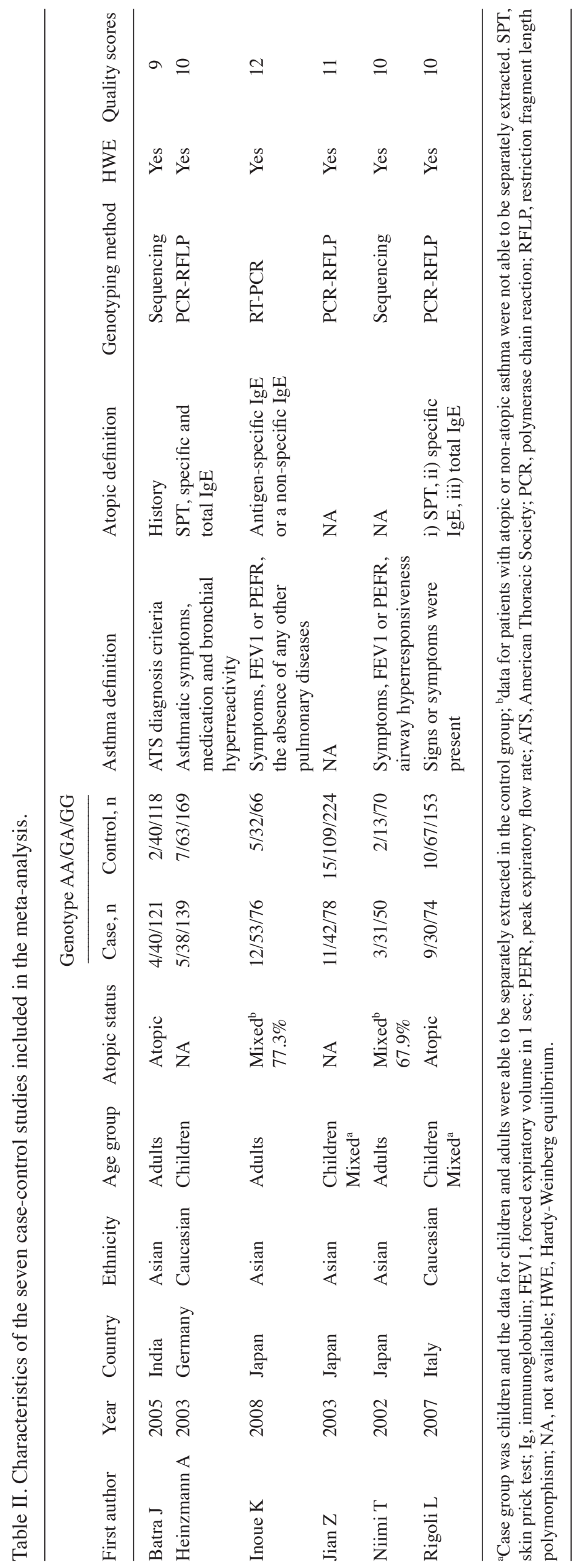




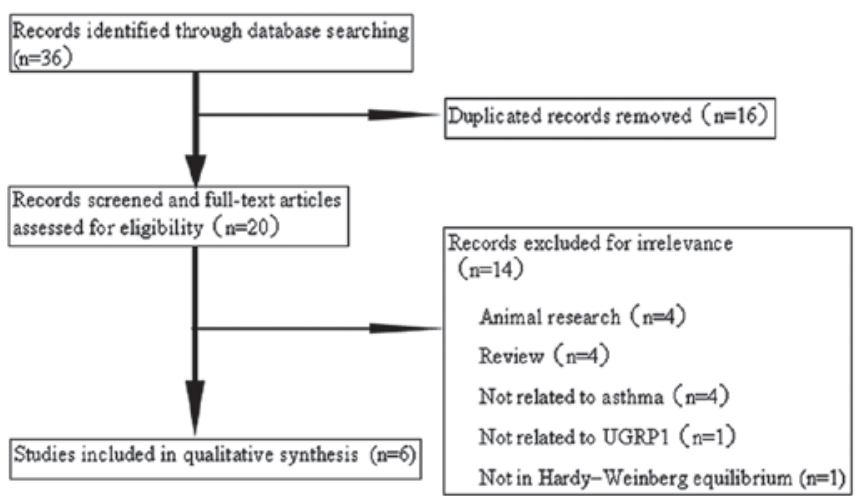

Figure 1. Flow of study identification, inclusion and exclusion. UGRP1, uteroglobin-related protein 1.

\section{Results}

Studies included in the meta-analysis. Fig. 1 outlines the selection process. Briefly, a total of 36 articles were identified in the initial search. Having reviewed the titles, abstracts and full-texts, and removed the duplications, six relevant articles were included in the meta-analysis. These eligible case-control studies contained 816 cases and 1,165 controls. Two studies investigated a Caucasian population and four investigated an Asian population. Three studies were performed with adults and three with children. Two studies included only patients with atopic asthma, two studies included patients with atopic asthma and those with non-atopic asthma (data for these patients were able to be separately extracted) and two studies did not offer detailed information with regard to atopic status. The characteristics of each study included in the meta-analysis are presented in Table II.

Meta-analysis of the UGRP1 gene-112G/A polymorphism and asthma. The meta-analysis results are shown in Table III. The combined results of all the studies showed that there were significant associations between the UGRP1-112G/A polymorphism and asthma risk in the genetic model of AA versus GG (OR, 1.76; 95\% CI, 1.12-2.78; $\mathrm{P}=0.01)$ and in the genetic model of AA versus $\mathrm{GA} / \mathrm{GG}(\mathrm{OR}, 1.70 ; 95 \% \mathrm{CI}, 1.09-2.67$; $\mathrm{P}=0.02$ ) (Table III and Fig. 2). In the subgroup analysis by ethnicity, significant associations were observed among Asians in the genetic model of A versus $\mathrm{G}$ (OR, 1.42; 95\% CI, 1.06-1.90; $\mathrm{P}=0.02)$, AA versus $\mathrm{GG}(\mathrm{OR}, 2.08 ; 95 \% \mathrm{CI}, 1.16-3.72 ; \mathrm{P}=0.01)$ and AA versus $\mathrm{GA} / \mathrm{GG}(\mathrm{OR}, 1.90$; $95 \% \mathrm{CI}, 1.07-3.38$; $\mathrm{P}=0.03)$; however, these associations were not observed in Caucasian populations (Table III and Fig. 3). The subgroup analysis by atopic status showed associations for A versus $\mathrm{G}$ (OR, 1.84; 95\% CI, 1.08-3.13; $\mathrm{P}=0.02)$ and $\mathrm{AA} / \mathrm{GA}$ versus $\mathrm{GG}(\mathrm{OR}$, 0.47 ; 95\% CI, 0.23-0.97; $\mathrm{P}=0.04)$ in the mixed atopic group (Table III). Subgroup analysis was also performed by age, but no associations were found.

Heterogeneity analysis. No heterogeneity was observed in the additive and dominant models, however, marked heterogeneity existed in the allelic and recessive models. Therefore, Galbraith plots were used to graphically evaluate the source of the heterogeneity. For the allelic model, one

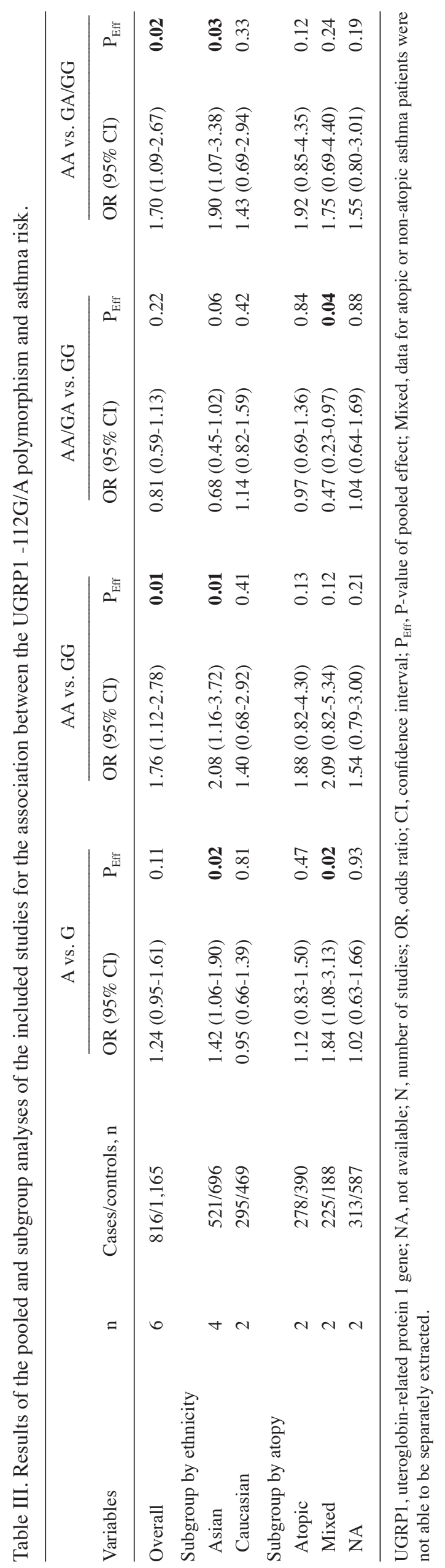


A

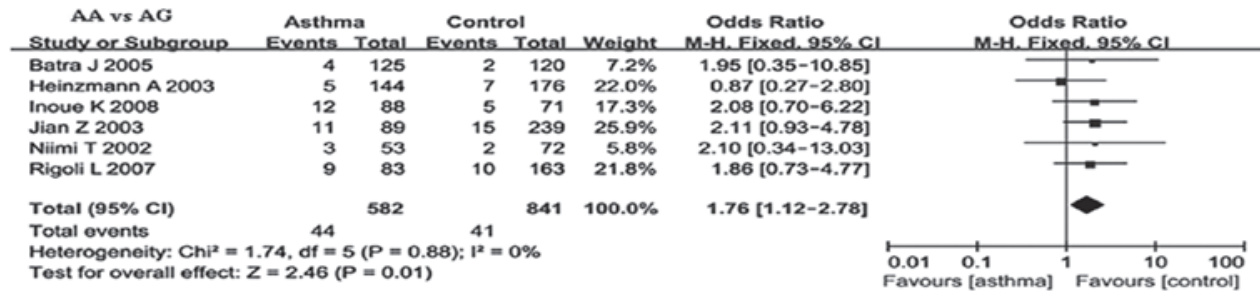

$\mathbf{B}$



Figure 2. ORs and 95\% CIs of individual and pooled results for the association between the UGRP -112G/A polymorphism and asthma for all the studies. (A) AA vs. GG; (B) AA vs. GA/GG. OR, odds ratio; CI, confidence interval; UGRP-1, uteroglobin-related protein 1.

A

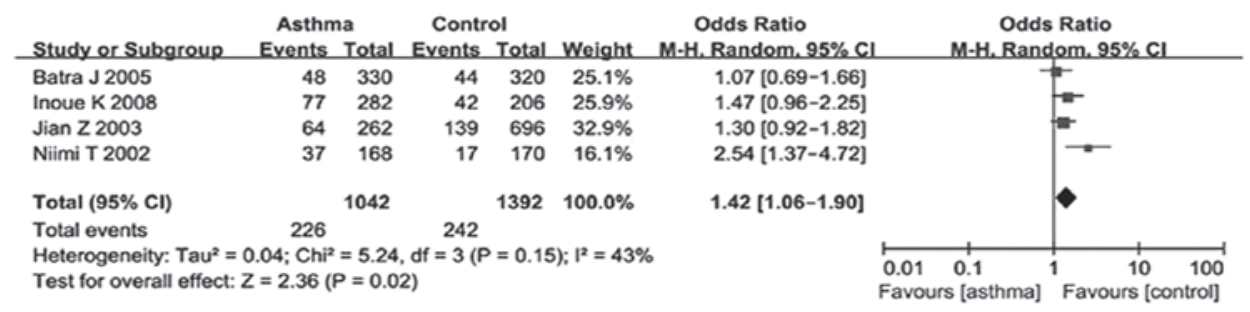

B

\begin{tabular}{|c|c|c|c|c|c|c|c|c|c|}
\hline Study or Subgroup & $\begin{array}{l}\text { Asthm } \\
\text { Events }\end{array}$ & Tetal & $\begin{array}{l}\text { Contre } \\
\text { Events }\end{array}$ & $\begin{array}{l}\text { ol } \\
\text { Total }\end{array}$ & Weight & $\begin{array}{l}\text { Odds Ratio } \\
\text { M-H, Fixed. } 95 \% \mathrm{Cl}\end{array}$ & $\begin{array}{r}\text { Odds } \\
\text { M-H,Fix }\end{array}$ & $\begin{array}{l}\text { s Ratio } \\
\text { ked. } 95 \% \mathrm{Cl}\end{array}$ & \\
\hline Batra J 2005 & 4 & 125 & 2 & 120 & $12.8 \%$ & $1.95[0.35-10.85]$ & & & \\
\hline Inoue K 2008 & 12 & 88 & 5 & 71 & $30.9 \%$ & $2.08[0.70-6.22]$ & & $=-$ & \\
\hline Jian Z 2003 & 11 & 89 & 15 & 239 & $46.1 \%$ & $2.11[0.93-4.78]$ & & 블 & \\
\hline Nlimi T 2002 & 3 & 53 & 2 & 72 & $10.3 \%$ & $2.10[0.34-13.03]$ & & & \\
\hline Total $(95 \% \mathrm{Cl})$ & & 355 & & 502 & $100.0 \%$ & $2.08[1.16-3.72]$ & & & \\
\hline Total events & 30 & & 24 & & & & & & \\
\hline \multicolumn{7}{|c|}{$\begin{array}{l}\text { Heterogeneity: Chi } i^{2}=0.01, d f=3(P=1.00): I^{2}=0 \% \\
\text { Test for overall effect: } Z=2.46(P=0.01)\end{array}$} & $\begin{array}{ll}0.01 \quad 0.1 \\
\text { Favours [asthma] }\end{array}$ & ${ }^{1} \underset{\text { Favours }[\infty}{10}$ & $\begin{array}{r}100 \\
\text { ontrol] }\end{array}$ \\
\hline
\end{tabular}

C



D

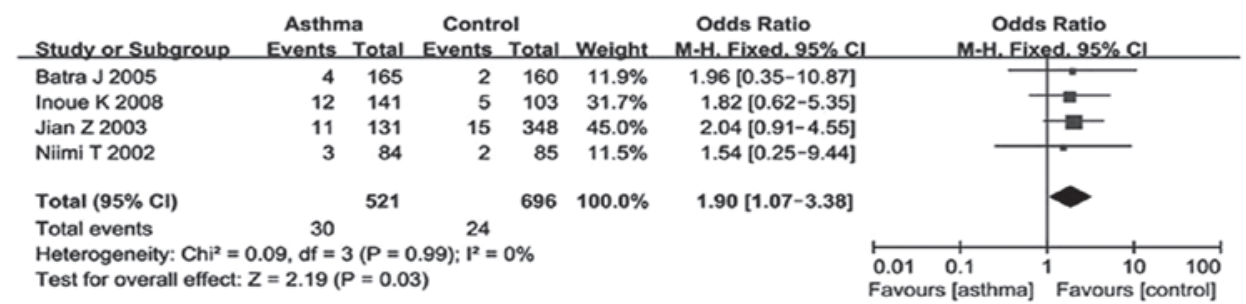

Figure 3. ORs and 95\% CIs of individual and pooled results for the association between the UGRP -112G/A polymorphism and asthma for the Asian subgroup. (A) A vs. G; (B) AA vs. GG; (C) AA/GA vs. GG; (D) AA vs. GA/GG. OR, odds ratio; CI, confidence interval; UGRP-1, uteroglobin-related protein 1.

study (5) was hypothesized to be the main contributor to the heterogeneity (Fig. 4).

Publication bias. Begg's funnel plots were used to investigate the potential publication bias of the studies. The funnel plot demonstrated evidence of asymmetry for the allelic model (Fig. 5). No evidence of publication bias was observed in other comparison models using Begg's funnel plots. In addition, no publication bias was revealed among the studies when using Egger's regression test $(\mathrm{P}=0.109,0.794,0.153$ 


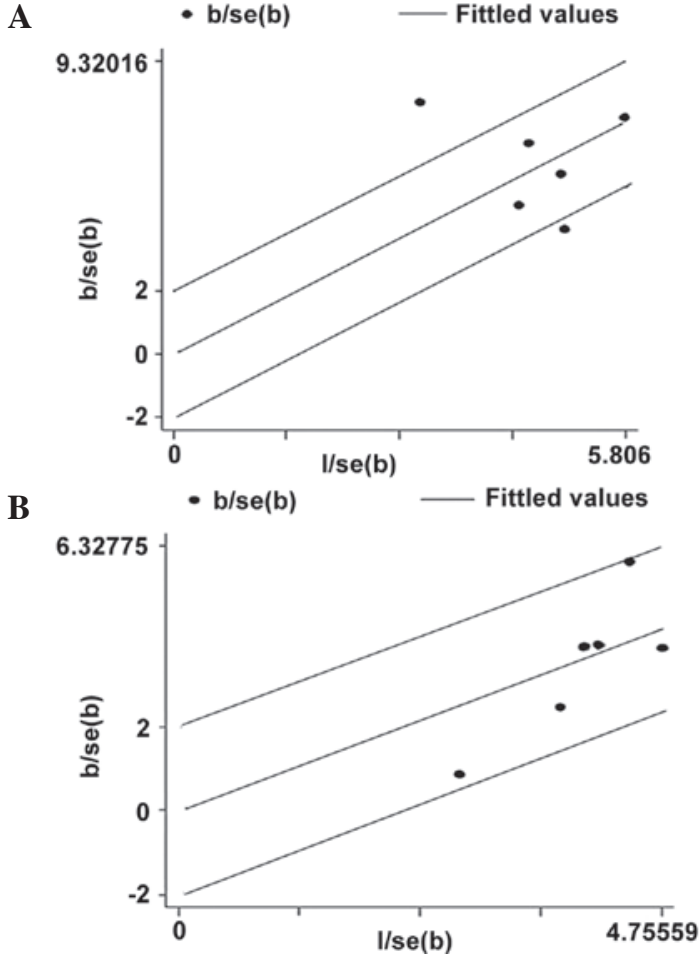

Figure 4. Galbraith plots of the association between the $-112 \mathrm{G} / \mathrm{A}$ polymorphism and asthma in the allelic and recessive models. (A) Allelic model (A vs. G). The outlying dot indicates the study of Niimi et al, 2002 (5). (B) Recessive model (AA+GA vs. G/G). se, standard error.

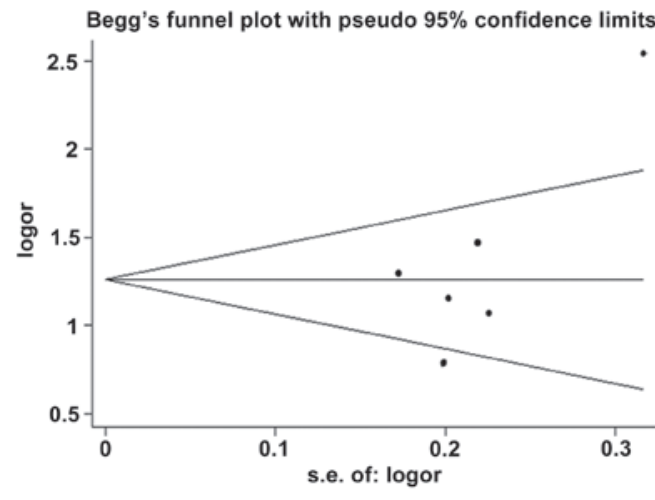

Figure 5. Association between the $-112 \mathrm{G} / \mathrm{A}$ polymorphism and asthma in all the studies for the allelic model (A vs. G). se, standard error; or, odds ratio.

and 0.482 for the allelic, additive, recessive and dominant models, respectively).

\section{Discussion}

Asthma is a complex pulmonary disorder that is caused by numerous genetic and environmental factors and is the result of genetic and environmental interaction. The hallmarks of asthma are airway inflammation, remodeling and hyperresponsiveness $(2,15)$. The UGRP1 gene was identified by Niimi et al (4), and is located in a chromosomal region harboring a number of genes involved in allergic diseases. UGRP1 is similar to CC16 with regard to its amino acid sequence and site of tissue-specific expression (4). As demonstrated by in vivo and in vitro studies $(6,16)$, CC16 functions as an anti-inflammatory agent. Similarly, UGRP1 has been suggested to exhibit anti-inflammatory functions. It has been shown that UGRP1 is associated with an increased risk for Graves' disease $(17,18)$. However, there have been confounding results with regard to the correlation between UGRP1 gene polymorphisms and asthma risk $(5,7,9,19)$. Therefore, in the present study, a comprehensive meta-analysis was conducted to examine the association between the UGRP1 gene $-112 \mathrm{G} / \mathrm{A}$ polymorphism and asthma risk.

The present meta-analysis of six articles, including 816 patients with asthma and 1,165 controls, investigated the association between the UGRP1-112G/A polymorphism and asthma risk. Overall, the pooled results revealed significant associations between the UGRP1-112G/A polymorphism and asthma risk in the genetic models of AA versus GG and AA versus GA/GG. To conduct a more comprehensive study of the correlation between the UGRP1-112G/A polymorphism and asthma, subgroup analyses were performed. In the subgroup analysis by ethnicity, significant associations with asthma were revealed among Asians in the allelic, additive and dominant genetic models. The allelic model suggested that carriers of the $\mathrm{A}$ allele, including the AA and AG genotypes, were at a 1.42-fold higher risk of asthma than $\mathrm{G}$ allele carriers. The additive model demonstrated that the AA genotype increased the risk by $108 \%$, indicating that individuals with the homozygous AA genotype were likely to have a higher risk of asthma than those with a GG genotype. Furthermore, the dominant model indicated that individuals with a homozygous AA genotype were likely to have higher risk of asthma than those with AG and $\mathrm{GG}$ genotypes $(\mathrm{OR}=1.90)$. However, these associations were not observed in the Caucasian subgroup. The ethnic differences may have been due to chance, since studies with small sample sizes are likely to have a low statistical power to detect slight effects. In the stratification by atopy, associations were observed for the allelic and recessive models in the mixed group. No significant associations were revealed for the age stratification.

In the present meta-analysis, heterogeneity existed in the allelic and recessive models. This issue may have affected the interpretation of the results. In order to explore the source of heterogeneity, Galbraith plots were produced for all of the studies. As shown in Fig. 4, it is possible that one study (5) may have been the main source of heterogeneity. The funnel plots were symmetrical, except the allelic genetic model, and it was indicated that there was no significant publication bias among the selected studies using Egger's test. Despite this, the meta-analysis results of the present study should be interpreted with caution, due to the following limitations: i) The number of studies included in the meta-analysis was small, with only two studies performed with a Caucasian population; ii) heterogeneity may have affected the meta-analysis; iii) although Egger's regression test was performed, publication bias may still have affected the analysis, as studies with negative results may not have been published; and iv) the meta-analysis was not able to assess gene-gene and gene-environment interactions.

To the best of our knowledge, this is the first meta-analysis conducted to explore the association between the UGRP1-112G/A polymorphism and asthma risk. All studies included in this meta-analysis were of a high quality, which was shown by the quality score assessment results in Table II. 
In conclusion, this meta-analysis indicated that the $-112 \mathrm{G} / \mathrm{A}$ polymorphism of the UGRP1 gene may be involved in asthma, particularly in Asian populations. In the future, more well-designed, high-quality studies are required to assess the role of the UGRP1-112G/A polymorphisms in the pathogenesis of asthma.

\section{Acknowledgements}

The authors thank Dr Fook T Chew (Department of Biological Sciences, National University of Singapore, Singapore), Dr E. Noguchi (Department of Medical Genetics, Institute of Basic Medical Sciences, University of Tsukuba, Ibaraki, Japan), Dr Mitsuru Munakata (Department of Pulmonary Medicine, School of Medicine, Fukushima Medical University, Fukushima, Japan) and Dr Shioko Kimura (Laboratory of Metabolism, National Cancer Institute, National Institutes of Health, Bethesda, MD, USA) for providing relevant information. This study was supported by a research grant from the Natural Science Foundation of Guangdong Province (no. 2012010009036).

\section{References}

1. Masoli M, Fabian D, Holt S and Beasley R; Global Initiative for Asthma (GINA) Program: The global burden of asthma: executive summary of the GINA Dissemination Committee report. Allergy 59: 469-478, 2004.

2. Mukherjee $A B$ and Zhang Z: Allergic asthma: influence of genetic and environmental factors. J Biol Chem 286: 32883-32889, 2011

3. Vercelli D: Discovering susceptibility genes for asthma and allergy. Nat Rev Immunol 8: 169-182, 2008.

4. Niimi T, Keck-Waggoner CL, Popescu NC, Zhou Y, Levitt RC and Kimura S: UGRP1, a uteroglobin/Clara cell secretory protein-related protein, is a novel lung-enriched downstream target gene for the T/EBP/NKX2.1 homeodomain transcription factor. Mol Endocrinol 15: 2021-2036, 2001.

5. Niimi T, Munakata M, Keck-Waggoner CL, et al: A polymorphism in the human UGRP1 gene promoter that regulates transcription is associated with an increased risk of asthma. Am J Hum Genet 70: 718-725, 2002.
6. Singh G and Katyal SL: Clara cells and Clara cell $10 \mathrm{kD}$ protein (CC10). Am J Respir Cell Mol Biol 17: 141-143, 1997.

7. Inoue K, Wang X, Saito J, et al: Plasma UGRP1 levels associate with promoter G-112A polymorphism and the severity of asthma. Allergol Int 57: 57-64, 2008.

8. Heinzmann A, Dietrich H and Deichmann KA: Association of uteroglobulin-related protein 1 with bronchial asthma. Int Arch Allergy Immunol 131: 291-295, 2003.

9. Jian Z, Nakayama J, Noguchi E, Shibasaki M and Arinami T: No evidence for association between the $-112 \mathrm{G} / \mathrm{A}$ polymorphism of UGRP1 and childhood atopic asthma. Clin Exp Allergy 33: 902-904, 2003

10. Rigoli L, Di Bella C, Procopio V, et al: Uteroglobin-related protein 1 gene $-112 \mathrm{G} / \mathrm{a}$ polymorphism and atopic asthma in Sicilian children. Allergy Asthma Proc 28: 667-670, 2007.

11. Batra J, Niphadkar PV, Sharma SK and Ghosh B: Uteroglobin-related protein 1(UGRP1) gene polymorphisms and atopic asthma in the Indian population. Int Arch Allergy Immunol 136: 1-6, 2005.

12. Andiappan AK, Yeo WS, Parate PN, et al: Variation in Uteroglobin-Related Protein 1 (UGRP1) gene is associated with allergic rhinitis in Singapore Chinese. BMC Med Genet 12: 39, 2011.

13. Thakkinstian A, McEvoy M, Minelli C, et al: Systematic review and meta-analysis of the association between \{beta\}2-adrenoceptor polymorphisms and asthma: a HuGE review. Am J Epidemiol 162: 201-211, 2005.

14. Hyun $\mathrm{MH}$, Lee $\mathrm{CH}$, Kang $\mathrm{MH}$, Park BK and Lee $\mathrm{YH}$ Interleukin-10 promoter gene polymorphisms and susceptibility to asthma: a meta-analysis. PLoS One 8: e53758, 2013.

15. Koppelman GH: Gene by environment interaction in asthma. Curr Allergy Asthma Rep 6: 103-111, 2006.

16. Arsalane K, Broeckaert F, Knoops B, Wiedig M, Toubeau G and Bernard A: Clara cell specific protein (CC16) expression after acute lung inflammation induced by intratracheal lipopolysaccharide administration. Am J Respir Crit Care Med 161: 1624-1630, 2000.

17. Chistiakov DA, Voronova NV, Turakulov RI and Savost'Anov KV: The $-112 \mathrm{G}>\mathrm{A}$ polymorphism of the secretoglobin $3 \mathrm{~A} 2$ (SCGB3A2) gene encoding uteroglobin-related protein 1 (UGRP1) increases risk for the development of Graves' disease in subsets of patients with elevated levels of immunoglobulin E. J Appl Genet 52: 201-207, 2011.

18. Song HD, Liang J, Shi JY, et al: Functional SNPs in the SCGB3A2 promoter are associated with susceptibility to Graves' disease. Hum Mol Genet 18: 1156-1170, 2009.

19. de Burbure C, Pignatti P, Corradi M, et al: Uteroglobin-related protein 1 and clara cell protein in induced sputum of patients with asthma and rhinitis. Chest 131: 172-179, 2007. 